In contrast to previous work, our study considers both meaning and mediation factors in the achievement-aspiration relationship. In a sample of graduate students ("academic-career aspirants"), we examine sex differences in the achievementaspiration relationship as they vary with type of academic achievement and professional aspirations, and as it is mediated by individuals' perceptions of their professional roles and their faculty's support. We find: (1) Women's achievementaspiration conversion is different from, but not necessarily lower than, men's. Rather, the strength and direction of the relationship vary with aspiration type (traditional versus alternative) and, to some extent, with specific types of academic achievement (e.g., paper publication and GPA). (2) The mediators of the achievement-aspiration relationship also vary by sex and aspiration type. Notably, women's aspirations for traditional career rewards are largely a function of their perceptions of the structural availability of job opportunity.

\title{
Achievement and Aspiration
}

\section{PATTERNS AMONG MALE AND FEMALE ACADEMIC-CAREER ASPIRANTS}

\author{
MARY FRANK FOX \\ University of Michigan
}

CATHERINE A. FAVER

University of Texas at Arlington

T

hat which one has already accomplished -achievementsprovide a basis for that which one hopes to accomplishaspirations. Yet, while achievement and aspiration levels are related, the associations are not comparable for men and women. A number of studies indicate that, compared to males, females require a higher prior achievement level to reach the same level of expectation for further performance. ${ }^{1}$ To put it another way, women's achievements translate into aspirations at a level lower than that of males. 
This sex-differential pattern is especially apparent in the school and academic environment, and has been observed throughout the educational life cycle: in elementary schoolchildren's aspirations for college attendance (Wylie, 1963), high school students' levels of occupational ambition (Marini and Greenberger, 1978), college students' predictions of course grades (Vaughter et al., 1974), and graduate students' aspirations for a university versus a junior college teaching career (Feldman, 1974).

Although these studies clearly document male-female differences in the level at which achievements translate into aspirations, they ignore both the multidimensional meaning and the mediating process of the achievement-aspiration relationship. In contrast, our study considers both the meaning of achievement and aspiration, and the mediating process as factors that influence and explain the achievement-aspiration relationship and its sex variation. In general, the mediating process refers to the intrapsychic and interpersonal events that affect the level at which achievements translate into aspirations. For example, the intrapsychic mediating process might include the effect of self-confidence and sense of competence on the achievementaspiration relationship. Interpersonally, the mediating process might include the cues received from others regarding the importance of prior achievement as an indicator of ability level.

Hence, we hypothesize that the achievement-aspiration translation occurs not only at a lower level for women, but that it is different also with respect to the type of aspiration sought, and the process mediating the relationship. More specifically, in a sample of graduate students, we examine sex differences in the achievement-aspiration relationship (1) as it varies with type, or meaning, of academic achievement and professional aspirations, and (2) as it is mediated by individuals' perceptions of their professional roles and their faculty's support. 
Our model of the achievement-aspiration relationship unfolds in three theoretical and analytical stages, each with related issues and questions:

Stage 1. First, we consider sex differences in the achievement-aspiration relationship, as it varies with specific achievements and types of aspirations.

In career choice and role performance, the sexes have been identified as having different work values and goals. Men have valued salary, prestige, and advancement opportunity. Women, on the other hand, have been relatively more concerned with the opportunity to help others, express personal identity, and make social contributions (Astin, 1975). Moreover, compared to men, women tend to be more interested in the affiliative aspects of achievement (Stein and Bailey, 1977), the intrinsic nature of the task (Astin, 1975), and the process, rather than simply the goal, of achievement (Veroff, 1977).

These gender differences in work values are consistent with the more global differences identified by Bakan (1966) as "agentic" versus "communal." Specifically, agentic achievement is characterized by self-protection, assertion, and mastery, while communal achievement emphasizes the motive and the value to be with rather than apart from others, and to gain rewards through interaction, rather than competition, with others. ${ }^{2}$

Such identification of sex-differential values and goals suggests that, in the academic environment, men and women may have quite different aspirations. More specifically, men may aspire to advancement, high salary, and prestige, while women may desire social contribution, accomplishment through collaboration, and the instrinsic rewards of task involvement.

Yet, by largely overlooking this multidimensional, and sexdifferential, meaning of accomplishments and goals, researchers may have underestimated the level at which women's achievements translate into aspirations. However, by distin- 
guishing accomplishment and goal categories, our study determines at this stage: (1) whether the achievement-aspiration relationship varies for different types of academic achievements (e.g., GPA, paper publication) and different types of professional aspirations (i.e., traditional versus alternative), and (2) whether there are systematic gender differences in these relationships.

Stage 2. Maintaining the distinction between types of achievements and aspirations, we next consider sex differences in the effects of certain social psychological variables on the achievement-aspiration relationship.

Little is known about the process by which external, structural possibilities and limitations affect one's internal motivations and aspirations. Nonetheless, certain aspects of the literature on professional development and its sex variation indicate, and prompt us to consider, the following factors as they mediate students' achievement-aspiration relationship:

(1) Clarity of educational and professional objectives: Although they are good students, women have not typically been socialized for career preparation. Thus, they have often entered graduate school by "default" (because of few suitable alternatives or encouragement from professors) rather than by "design" (clear-cut career objectives; see Angrist and Almquist, 1975; Bernard, 1964). We expect that lack of clear-cut objectives is likely to depress the level at which prior achievements translate into future aspirations.

(2) Certainty about the significance of one's field and one's prospects within it:

(a) If, as the literature on work values suggests (Astin, 1975), women are more concerned with the social and personal significance of their work, then personal beliefs about the significance of one's field should exert a stronger effect on the achievement-aspiration relationship for women than for men.

(b) Further, because aspiration level is related to the prospects for advancement (Kanter, 1977), and because 
women's prospects are limited both in graduate school (Holmstrom and Holmstrom, 1974) and in their academic careers (Hornig, 1979), we expect aspirations, relative to achievements, to be especially depressed among women.

(3) Perceived control over educational and professional prospects and outcomes: Research suggests that individuals' expectations for future success are affected by their causal attributions to internal or external factors (i.e., by their sense of internal versus external control; Frieze et al., 1978). Likewise, we might expect individuals' perceived control over outcomes to mediate the conversion of achievement into aspiration. More specifically, we expect that a strong sense of personal efficacy (perceived control over outcomes) will raise an individual's aspirations for professional achievement relative to prior demonstrated competency and success.

(4) Commitment to the fulfillment of educational and professional objectives: It seems obvious that aspiration level is related to an individual's commitment to the preparation for and pursuit of a career. Yet, despite demonstrated commitment, female graduate students report that their dedication is not taken seriously by their departments (Holmstrom and Holmstrom, 1974). As a consequence, we might expect female students, accordingly, to lower their aspirations, despite high achievements.

These items-clarity, certainty, control, and commitmentreflect perceptual assessments of social-structural realities, and hence represent factors that are both social (external) and psychological (internal) mediators of the achievement-aspiration relationship. In other words, although these items are individual factors, their sex-differential level and importance are derived from sex-differential opportunity structures, and hence these perceptions are rooted in social realities. By examining these mediators, our study can determine the process by which women's aspirations are raised or lowered at a critical juncture in their academic careers. Hence, at this second analysis stage, we determine the effects of these social 
psychological mediators as they vary (1) with different types of achievements and aspirations, and (2) by sex.

Stage 3. Finally, we consider sex differences in the effects of perceived faculty support on the achievement-aspiration relationship. We determine, that is, the effect of faculty support variables on the achievement-aspiration relationship of the previous analysis stage.

Faculty sponsorship and support are central components of graduate students' socialization into, and hence aspirations for, the professional academic role. Student-faculty interaction not only raises aspirations directly (Feldman, 1974), but may also operate indirectly (Reskin, 1978) by enhancing professional certainty, clarity, commitment, and control.

Yet, faculty support is not comparable for male and female students. To begin with, female students have less contact and communication with faculty members and research advisers (Holmstrom and Holmstrom, 1974). Moreover, women's interaction with faculty is limited not only in quantity, but also in quality. In their faculty interaction, women tend to relate as students, while men interact as colleagues or apprentices (Feldman, 1974), in a far more relaxed, informal, and egalitarian relationship with their advisers (Kjerulff and Blood, 1973). Accordingly, male graduate students are more likely to be invited by faculty members to co-author papers, attend conferences, and meet members of the profession (Brodsky, 1974).

Examining the faculty support effects at this stage, we ask specifically (1) whether the effect of faculty support on the achievement-aspiration relationship varies with type of achievement and aspiration; (2) whether faculty support alters the mediating effects of the social psychological variables; and (3) whether there are systematic gender differences in these relationships. 


\section{METHOD}

\section{DATA}

The data for this study come from a 1977-1978 mail survey of graduate students, conducted by the Office of Career Counseling and Placement at a major midwestern university. The data represent a survey of students within the humanities, social sciences, and natural, physical, and biological science departments within this university. The survey's sample excluded students in professional programs, such as medicine, pharmacy, social work, education, and engineering-an appropriate exclusion for our particular analyses, since we focus on the achievement-aspiration relationship primarily as it operates among aspirants for an academic career.

From these data, we eliminate master's degree students, and restrict analyses to students pursuing the Ph.D. This allows us to limit our achievement-aspiration study to a more comparable male and female group who, by definition, share both the achievement of admission to a competitive university and the aspiration for this high degree level. ${ }^{3}$ Moreover, for the purposes of our study, this particular graduate student sample represents a group with both currently manifest attainments and at least nascent professional goals; hence it represents a group at a pivotal life-cycle stage at which both present achievement and future aspiration levels are highly salient.

These students constitute a group of 587: 63\% males and $37 \%$ females. This group's sex distribution is almost the same as the population from which it was drawn. ${ }^{4}$

\section{VARIABLES}

\section{Dependent Variables: Professional Aspirations}

The aspiration variables form two categories: traditional and alternative. Traditional aspirations are represented by an 
index measuring striving for the customary rewards of the academic profession: highest possible income, rapid promotion, tenure, and collegial recognition. Alternative aspirations are measured in terms of an index assessing students' desire to gain the intrinsic rewards of serving others, working with people, and doing socially important work within a profession. ${ }^{5}$

Thus, the traditional category comprises aspirations for fulfillment of the standard academic role as a well-paid, respected, and securely tenured professor. Achievement of these goals typically requires social comparison, competition, and mobility (Bakan, 1966; Parsons and Goff, 1978). The alternative aspiration category, on the other hand, integrates social and affiliative with achievement and performance goals.

A two-sample $t$ test revealed that, among our respondents, adherence to these aspiration types does, indeed, vary with sex: Women have significantly higher (.000) alternative, and men significantly higher (.028) traditional, aspirations. ${ }^{6}$

\section{Independent Variables}

Achievements. Students' achievements are represented by five academic attainments: (1) grade point level, (2) presentatation of a professional paper, (3) paper publication, (4) research assistantship, and (5) teaching assistantship.

Grading standards vary among departments; therefore interdepartmental GPAs are noncomparable, and an "A-" in one department may be equivalent to a " $\mathrm{B}+$ " in another. For this reason, we obtained the mean grade point levels for the departments represented in our study, and standardized each respondent's grade level in terms of his or her respective departmental mean.

For the other four (items 2-5 above) achievements, we coded students' attainments as dummy variable scores, wherin the presentation or publication of a paper, and an appointment 
held, at some time, as a research or teaching assistantship, are each coded as the 1 value.

Clarity, Certainty, Commitment, and Control. These variables, referred to in shorthand as the $C$ variables, are attitudinal and perceptual mediators of the achievementaspiration relationship. These mediators form four categories:

(1) Clarity refers to students' clearness of purpose in the decision to enter graduate school. "Low clarity" (entry "by default") is measured by an index of students' response that (very or somewhat) important issues in the entry decision included graduate school as a place "to get one's head together," an "easy program to get into," a place where "one's friends were going," or an alternative where "nothing better existed."

In contrast, "high clarity" designates graduate school entry by design rather than default, and is measured by the response that desire to teach, to do research, or to pursue some specific set of career goals figured as very or somewhat important in the decision to undertake graduate study.

(2) Certainty refers to students' assessments of the importance of the discipline and one's prospects within it. "Discipline certainty" is measured in terms of perception about the importance (low to high) of the discipline's issues-to the respondent, and to (respondent's) society. "Job certainty" represents employment prospects perceived as very good or good (compared with fair or poor), with the very good to good prospects taking a dummy variable score of 1 .

(3) Commitment is represented by students' self-ratings of their commitment (low to high) to completing the doctoral degree program.

(4) Control over professional destiny is designated by a dummy variable measuring students' agreement (versus disagreement) that they are generally able to make a follow through with plans. 
Faculty Interaction and Support. As the other set of mediators of the achievement-aspiration relationship, these variables measure the student's faculty interaction and support system. ${ }^{7}$

Faculty interaction represents students' assessment of the quality of interaction with faculty as good to excellent (versus fair to poor).

Faculty support indicates the availability (versus absence) of a single faculty member for three different types, and hence three measures, of support: (1) general guidance, (2) supervision of study, (3) job help. Each of these measures takes a dummy variable form wherein good to excellent support assumes the 1 value.

\section{Control Variable: Field of Study}

In order to control for discipline or field variations in the achievement-aspiration relationship, we include a field of study variable. Field constitutes three categories: natural sciences, social sciences, and arts and humanities. ${ }^{8}$ The natural and social science categories each take dummy variable form, with the arts and humanities as the excluded category in regression analysis.

\section{ANALYSIS TECHNIQUE}

The aspiration relationships are expressed in multistage regression models, with separate equations for aspiration type and sex. The first, baseline model expresses the relationship between aspiration and achievement levels. The second-stage expression includes the addition of the social psychological (C) variables, and the third stage, the addition of the faculty support variables. These multistage models do not posit a particular causal order among the variables. Rather, the focus is on analysis of the relationship between achievement and aspiration levels, and the modification of that relationship by the social and psychological support variables. ${ }^{9}$ 
The multistage models permit this assessment by allowing us to compare baseline with subsequent coefficients and $\mathrm{R}^{2}$ levels. This, then, enables us to determine the extent to which the achievement-aspiration effects are independent of, or, conversely, mediated by, variations in social psychological conditions and levels of faculty support. Further, the separate equations for sex and aspiration type permit us to analyze the data relationships for men contrasted with women, and for "traditional" versus "alternative" aspiration types.

At each stage of the analysis, field of study is included as a control variable. In this way, we control for the effects of differences in academic fields, while assessing sex variation in the achievement-aspiration relationship.

\section{FINDINGS AND DISCUSSION}

An overview of our findings shows that the achievementaspiration relationship varies with the type of aspiration and the sex of the aspirant.

While the achievement-traditional aspiration relationship is stronger for men, higher achievers do tend to have higher traditional aspirations among both sexes. But alternative aspirations represent another matter: For these, higher achieving women tend to have higher aspirations, but men do not. Hence, for women, achievements tend to translate into both traditional and alternative aspirations; for men, high achievements are associated with traditional, but not with the alternative, aspirations.

Further, we find that, as separate accomplishments, certain achievements are related to traditional and others to alternative aspirations, and that these patterns also vary by sex.

Finally, we find that the achievement-aspiration relationship is subject to variation in the students' commitment, clarity, certainty, and control over professional goals and objectives, and to variation in the quality and level of faculty support and interaction. 


\section{TRADITIONAL ASPIRATIONS}

\section{Stage I: Aspirations as a Function of Achievements Alone}

For both sexes, there is a positive relationship between achievement and aspiration for traditional academic rewards, but as indicated by the $R^{2}$ values, the relationship is stronger among males (Table 1). Moreover, specific achievements have sex-differential effects on aspirations:

Professional paper experience is the most important predictor of traditional aspirations for both sexes, but the importance of the particular type of experience differs for the two sexes. For men, it's paper publication that is associated with high aspirations; for women, it is presentation. Yet, only for males is the paper experience a statistically significant variable.

\section{Stage II: Aspirations as a Function of Achievements + C Variables}

With the addition of indicators of professional clarity, certainty, commitment, and control, the predictive strength of traditional aspirations strengthens by more than $135 \%$ for men ( $\mathrm{R}^{2}$ change, .069 to .162) and $111 \%$ for women (.044 to .093). Thus, the predictive strength of the male model continues to be higher (Table 1).

The addition of these predictors tends to increase rather than decrease the coefficient levels of men's achievementsGPA, paper presentation, and research and teaching assistantships-and hence these achievements become more important determinants of men's aspirations for traditional reward and recognition (Table 1). Still, only paper publication is a statistically significant determinant.

For women, on the other hand, the addition of the $\mathrm{C}$ variables has an opposite effect: These variables further decrease, rather than increase, the aspiration-determining 
TABLE 1

Multiple Regressions of Traditional Aspirations of Variables of Stage I, Stage II, and Stage III, by Sex

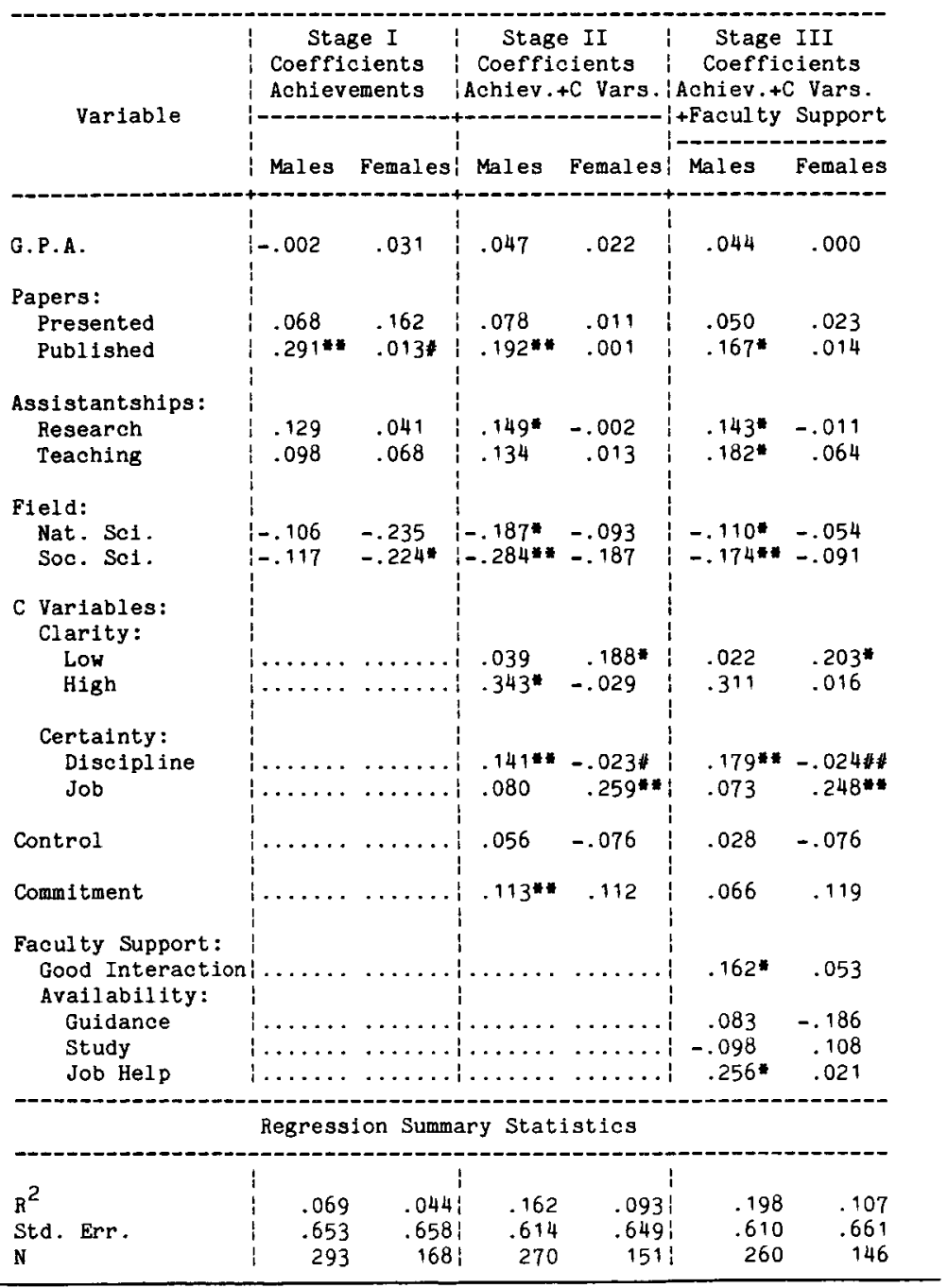

* Significant at $\leqslant .10$.

$\star *$ Significant at $\leqslant .05$.

\#Significant difference of $M-F$ coefficients at $\leqslant .10$.

\#\#ignificant difference of $M-F$ coefficients at $\leqslant .05$. 
strength of the achievements (Table 1). This suggests that the relatively weak achievement-aspiration relationship among women is partially a function of their mediating attitudes and perceptions, rather than their achievements alone. Thus, this second analysis stage emphasizes the weaker (independent) effect of the achievements for female, compared to male, traditional aspirations.

By controlling for the effects of achievements, this model also shows the effects of the $\mathrm{C}$ variables on the aspirations themselves. Among the males, the Cs are positively associated with traditional aspirations, with high clarity (entry by design), discipline certainty, and degree commitment emerging as the important $\mathrm{C}$ factors.

For women, the $\mathrm{C}$ variables do not have a consistent aspiration effect. Nevertheless, the big $\mathrm{C}$ factor for women is job-prospect certainty, and this is strongly positive in its association with female aspirations for traditional rewards. This finding suggests that aspirations are partly a function of prospects for the realization of ambition, and hence highlights the importance of access and opportunity (Kanter, 1977) as factors in the formation of women's occupational aims and goals.

Regarding the net effects of field on traditional aspirations, we find that among males, the social and natural sciences are significantly negative in their association with traditional aspirations. This suggests that, in social and natural sciences as opposed to arts (the dummy variable comparison category), male graduate students are unlikely to translate high achievements into aspirations for traditional academic attainments and rewards.

\section{Stage III: Aspirations as a Function of} Achievements + C Variables + Faculty Support

The addition of faculty-support variables further widens the difference in the predictive strength of the male and female 
models, empasizing again the stronger relationship between achievements and traditional aspirations among the men. Yet, four of the five male achievement coefficients drop, indicating that there is a covariation of achievement and faculty support. Indeed, while paper publication is no longer significantly related to men's traditional aspirations, the availability of faculty support in securing a job does significantly raise aspirations for traditional rewards (Table 1).

Further, men's C coefficients drop proportionately more than do their achievement coefficients, suggesting that faculty support can substitute, or "make up," for low C levels in raising men's aspirations. Hence, when faculty-support variables are controlled, discipline certainty is the sole $\mathrm{C}$ factor, becoming a stronger positive predictor of traditional aspirations among males (Table 1).

Among females, as opposed to males, the addition of the faculty-support variables creates greater proportional changes in their achievement coefficients, thus indicating a stronger covariation of achievement and faculty support for women. In particular, the female GPA coefficient, which was higher than the male level at Stage I, now declines considerably and is much weaker than the comparable male declines considerably and is much weaker than the comparable male coefficient. This suggests that the importance of grades to women's traditional aspirations is a function of the faculty support recieved by women who are good students.

Yet, women's C coefficients change very little from Stage II to Stage III, and this indicates that faculty support does not affect women's aspirations by altering C-variable levels, as it does for men.

Moreover, the really notable net effect of women's traditional aspiration model is a certainty variable - certainty, that is, of job prospects. Women with optimistic perceived job prospects tend to have high traditional aspirations, independent of how they are currently faring in achievement level, faculty support, or the other indicators of professional clarity, 
control, and commitment. We find, that is, that job-prospect certainty represents a significant effect net of achievements, and net of all other variables, as well. Job certainty emerges as the critical female factor, impervious to the influence of the other variables in the traditional aspiration model, and thus further indicates the importance of access and opportunity in the formation of women's aims and aspirations. ${ }^{10}$

In summary, our multistage model for traditional aspirations both supports and expands prior research on the sexdifferential achievement-aspiration relationship. For these traditional benchmarks of success, we find that male achievements 2 do translate into aspirations at a higher than female level. Of the achievements included in our model, professional paper publication and teaching assistantship are important determinants of men's aspiration levels. For women, however, high achievement does not convert automatically into traditional aspirations. Instead, the women's aspirations for the traditional rewards of academia are largely a function of their perception of the structural availability of those rewards in the job market; hence, our data suggest that the women's weaker achievement-aspiration relationship is strongly related to their largely accurate (Hornig, 1979) perceptions of limited opportunity.

\section{ALTERNATIVE ASPIRATIONS}

\section{Stage I: Aspirations as a Function of Achievements Alone}

We found earlier that achievements are better predictors of male than female aspirations for traditional reward and recognition. Now, however we find that for alternative aspirations-emphasizing the service, significance, and interpersonal quality of the work - the predictive strength of achievements is twice as strong for women $\left(R^{2}=.078\right)$ than for men $\left(R^{2}=.042\right.$; Table 2). 


\section{TABLE 2}

Multiple Regressions of Alternative Aspirations on Variables of Stage I, Stage II, and Stage III, by Sex

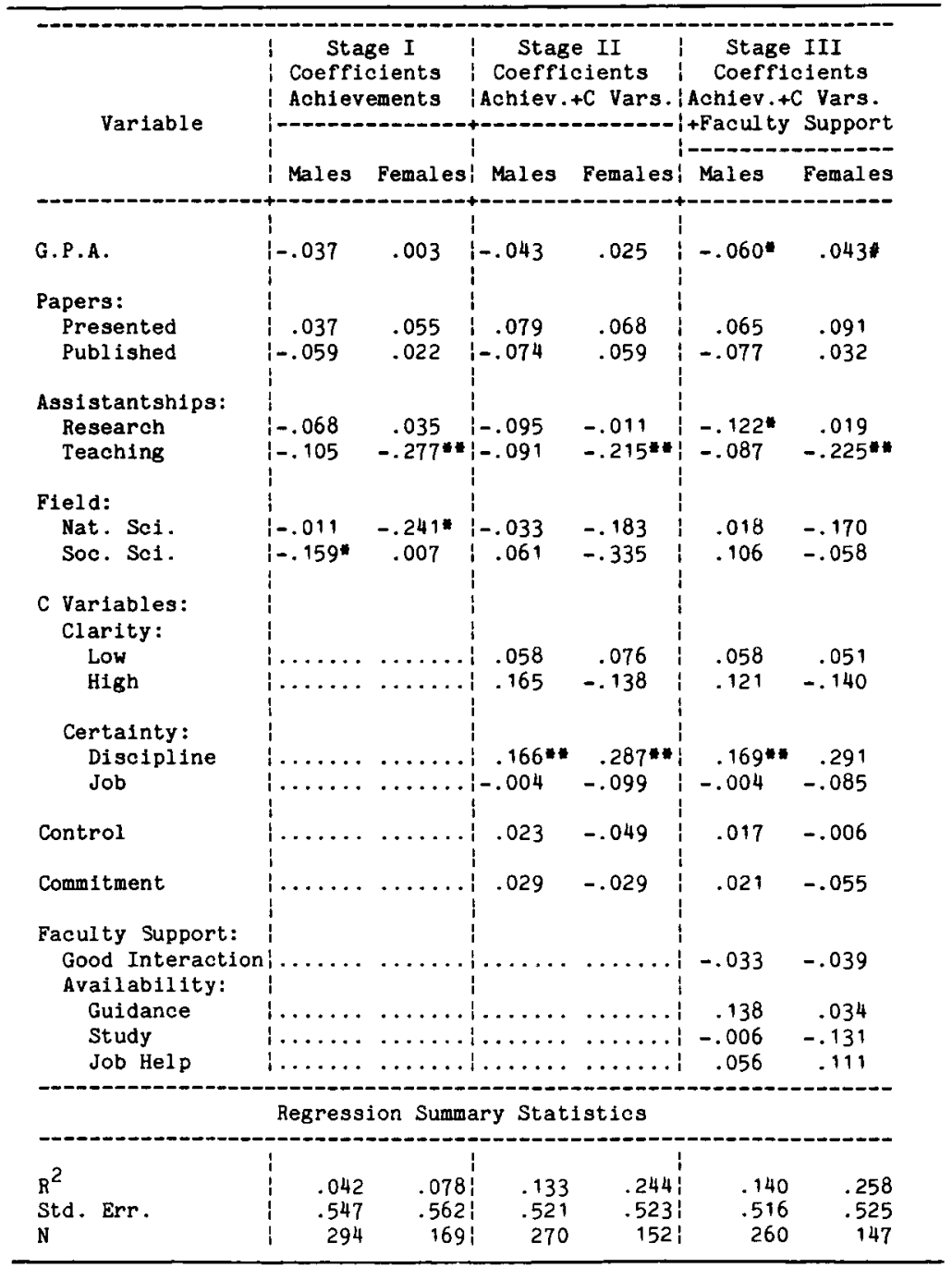

$\star$ Significant at $\leqslant .10$.

$\star \star$ Significant at $\leqslant .05$.

\#Significant difference of $M-F$ coefficients at $\leqslant .10$. 
Further, the direction of the alternative aspiration relationship differs by sex. In general, achievements are positive predictors of alternative aspirations among women, and negative predictors among men. Thus, high-achieving males are slightly disinclined toward the rewards of service, work with others, and social contribution. Despite this pattern, the only statistically significant achievement coefficient is the teaching assistantship for women, and this is strongly negative in its association with their alternative aspirations (Table 2).

\section{Stage II: Aspirations as a Function of Achievements + C Variables}

When the $C$ variables are added, the predictive strength $\left(R^{2}\right)$ of both male and female alternative aspirations rises sharply. But the strength of the female model increases proportionately more; hence, the female model remains stronger (Table 2).

Moreover, the addition of the $\mathrm{C}$ variables emphasizes the sex-differential achievement-alternative relationships found in Stage I. In general, the achievement variables continue to be negatively associated with alternative aspirations for males, and positively associated for females. Further, the teaching assistantship among women remains the sole significant achievement coefficient. Thus, the baseline relationships of Stage I may not be attributed to covariation of the achievements and $\mathrm{C}$ variables in either the male or female group.

With achievement levels controlled, we find further that discipline certainty is strongly positive in its association with alternative aspirations for males and females, alike. For both genders, certainty about the worthiness of one's discipline may be strongly related to alternative aspirations because, to some extent, both variables reflect concern with service and significance in work. 


\section{Stage III: Aspirations as a Function of} Achievements + C Variables + Faculty Support

With the addition of faculty support variables, the predictive strength of the male alternative aspiration model increases more proportionately, but still remains much weaker than that of the female model (Table 2).

Moreover, the sex-differential direction of the achievement-alternative aspiration relationship remains, and, for some achievement coefficients, it increases (Table 2). Most notably, the sex difference in GPA effect, as a negative predictor of male and positive predictor of male and positive predictor of female alternative aspirations, approaches statistical significance. This finding supports the notion of a sexdifferential meaning of specific achievements as they affect the achievement-aspiration relationship.

Recall from the traditional aspiration model that when the $C$ variables and faculty support are controlled, GPA is a much stronger, though not significant, positive predictor for males than females. But in the alternative aspiration model we find a different relationship: For these aspirations, high grades are positively related to aspirations for women but negatively related for men. Thus, our data suggest that high grades may translate into different and sex-typed aspirations-advancement for men and service for women.

Further, with the addition of faculty support variables, as with $\mathrm{C}$ factors, the negative relationship between the teaching assistantship and alternative aspirations continues to be strong and statistically significant for women (Table 2). This negative association reminds us that a desire for service, social contribution, and working with others need not be expressed primarily through teaching. Indeed, other aspects of academia offer strong opportunities for realization of these aspirations.

Finally, we find that the addition of faculty-support indicators does not greatly alter the alternative aspiration effects of 
the $\mathrm{C}$ variables (Table 2). Discipline certainty remains the single factor most strongly and positively related to both male and female alternative aspirations.

In summary, our model for alternative aspirations indicates that, in contrast to traditional aspirations, achievements are better predictors for women than men; moreover, while the achievements are positively associated with women's alternative aspirations, they are negatively associated with men's.

In addition, the model suggests the sex-differential meaning of certain achievements as well as aspirations; hence, it indicates the multidimensional meaning of the achievementaspiration relationship.

\section{CONCLUSIONS}

While the study's findings are suggestive, rather than definitive, they do point to important considerations and implications for the achievement-aspiration relationship:

(1) The level at which achievements translate into aspirations is different, but not necessarily lower, for women compared to men. Rather, for both sexes the strength and the direction of the achievement-aspiration relationship vary with aspiration type and, to some extent, with specific achievements.

For males, achievement is positively associated with aspirations for traditional rewards, and negatively, but weakly, associated with alternative, "service" aspirations. This may reflect encouragement for academically achieving males to aspire to positions of high income and prestige, rather than service.

For females, achievement is positively associated with both types of aspirations, but the relationship is stronger for alternative aspirations. In fact, the predictive strength of the model for women's alternative aspirations is slightly greater than that for men's traditional aspirations. Thus, we suggest 
that earlier studies, reporting a sex-differential achievementaspiration conversion favoring men, may have underestimated the strength of the relationship for females, by failing to consider certain alternative aspiration types.

Our findings also suggest some sex-differential meaning of specific achievements, since the achievement-aspiration relationship varies with specific achievements as well as aspiration types. Hence, achievements such as grades and teaching experience may have different subjective meanings for men and women, and thus may vary in their implications for the strength and type of aspiration.

Further, our findings point to the role of structural encouragement and support in explaining sex differences in the achievement-aspiration relationship. Specifically, because of sex-differential opportunity structures, men's early achievements are more likely to lead to subsequent attainments of wealth, power, and prestige, while women's early attainments are more likely to result in achievement through service and support. Moreover, individuals' aspirations "adjust" to fit their opportunities (Kanter, 1977). Hence, given equivalent achievement levels, each sex shows higher aspirations within the sextyped, traditionally "appropriate" aspiration category. By implication, social and political policies that would alter opportunities and incentives for men and women would, correspondingly, change the sex-differential achievementaspiration relationship.

(2) The process that mediates the achievement-aspiration relationship also varies with sex and aspiration type. For women, the achievement-traditional aspiration relationship results partially from the covariation of achievement with faculty support, and especially covariation with certainty about job prospects. In other words, given the structural constraints on women's opportunities, any supports greatly encourage high-achieving women to aspire to the rewards associated with the traditional "male" career. ${ }^{11}$ In contrast, the achievement-aspiration relationship among males is more 
direct, although faculty support does enhance the conversion process by substituting for low $\mathrm{C}$ factors.

For alternative aspirations, on the other hand, the achievement-aspiration relationship is less subject to change through variance in professional clarity, certainty, commitment, and control, and faculty support. This is true for both sexes.

(3) The social psychological or perceptual (C) factors, themselves, also have important sex-differential aspiration effects. Among men, high discipline certainty is related to both traditional and alternative aspirations, while job-prospect certainty does not figure strongly in either male aspiration type. Among women, however, high discipline certainty is related to alternative, but not traditional, rewards, while job certainty is the single factor most strongly related to women's traditional aspirations.

This pattern most likely reflects sex-differential opport unity structures and core values. Hence, a woman who believes in the worth of her discipline knows she will be "allowed" to contribute through service. But she may aspire to traditional rewards of salary, prestige, and advancement only when job prospects are certain.

Regardless of their achievement levels, however, men as a group have better job prospects than do women. The more evenly certain prospects for males may obliterate any particular effect of job certainty on their expectations for either traditional or alternative reward. On the other hand, especially high discipline certainty might encourage men to transcend their culturally expected and supported traditional aspirations, and thus extend their aspirations to service and association, as well.

\section{NOTES}

1. In a causal sense, aspirations may affect achievement levels, as well as vice versa. Yet, while our focus is on the achievement-aspiration relationship rather than causal association, in this study we conceive of achievements translating into 
aspirations, rather than the other way around. In one of the few longitudinal analyses on the topic, Williams (1972) reports that aspirations do tend to depend on achievement levels.

2. Lipman-Blumen and Leavitt (1976) also have created a typology in which achievement orientation is characterized according to several dimensions, including direct versus vicarious, intrinsic versus instrumental, and contributing versus competitive. However, in making these classifications, these researchers assume that women's expected affiliative achievement is necessarily passive, indirect, and vicarious. We propose, on the other hand, that achievement may be affiliative (i.e., communal or alternative), yet active and direct.

3. Because the sampled university is a highly selective and competitive institution, findings may not generalize to graduate students in smaller and minor institutions. However, the majority of $\mathrm{Ph}$.D. candidates are, indeed, enrolled in a few giant research universities (Mandell, 1977), not unlike the institution sampled.

4. Within the population, $65 \%$ of the doctoral students are male and $35 \%$ are female.

5. More specifically, the traditional aspirations are measured by the mean of respondents' level of commitment (none at all, slight, strong, or very strong) for earning (1) "the highest fair income for services and activities performed"; (2) "professional recognition for services and activities performed"; (3) "tenure"; and (4) "quick promotion." The alternative aspirations are measured by the mean of respondents" level of commitment to (1) "performing activities which service others' individual and collective needs"; (2) "working with people rather than strictly with ideas"; and (3) "doing work of vital social importance."

We constructed these indices of aspiration types from data collected and coded by the university's Office of Career Planning and Placement. Since we did not design the questionnaire or conduct the pretests ourselves, tests of reliability had to be limited to the literature (Bakan, 1966; Lipman-Blumen and Leavitt, 1976; Parsons and Goff, 1978) indicating the multidimensionality of aspirations and achievements. This literature also suggests the validity of the two aspiration types. Additional validity tests included our analysis of the correlation among the items within each aspiration index.

6. Because this article focuses on the relationship between achievement and aspiration, rather than simply the sex-differential values of the achievement, social psychological, and faculty support variables, we omit inclusion of a table with the means and standard deviations of the variables themselves. The interested reader may obtain these measures from the authors.

7. While we acknowledge findings about the importance of friendship as well as faculty interaction and support (Dowdall and Boneparth, 1979), we do not have access to these other support variables.

8. Among our surveyed departments, the natural sciences are represented by biological science, chemistry, mathematics, physics, and statistics; the social sciences by anthropology, economics, political science, psychology, and sociology; and the arts and humanities by classics, English, history, linguistics, philosophy, and romance languages.

9. Given our focus, the order in which we consider the independent variables could be only: Stage I, achievements; Stage II, either (a) achievements and C variables or (b) achievements and faculty support; and Stage III, achievements, Cs, and faculty support together. We choose IIa rather than IIb because the former allows us to examine the effect of faculty support upon the Cs. Given the salience of faculty suport 
and interaction for graduate students, we are interested in observing how the addition of faculty-support variables might change both the coefficients for the social psychological variables and the explained variation in the dependent aspiration variables.

10. Furthermore, compared to female graduate students in less selective universities, the women in our sample may have bettern than average job prospects. Thus, we speculate that for female Ph.D. students in less selective universities, the lack of job prospects may act as an even greater deterrent to traditional aspirations.

11. In light of recent affirmative action movements, our findings raise the question of whether women's objective job prospects and faculty support have increased, especially subsequent to the (1977-1978) gathering of these data. Recent data on faculty hiring (Hornig, 1979) indicate only small proportional increases in female faculty. This, in turn, suggests limited opportunities for the cultivation of female students' traditional aspirations through female faculty role models.

Moreover, while further literature on faculty support is unavailable for the most recent period, information provided by female graduate students suggests the continuation of sex-differential support. Specifically, the experience of the senior author as a regional coordinator of Sociologists for Women in Society indicates that female graduate students report particularly that male graduate students are more likely to be invited by faculty to coauthor papers, attend conferences, and the like. Nevertheless, attempts by faculty to avoid sex-differential treatment of graduate students may be occurring as a result of heightened awareness of discrimination against women.

\section{REFERENCES}

ANGRIST, S. S. and M. E. ALMQUIST (1975) Careers and Contingencies: How College Women Juggle with Gender. New York: Dunellen.

ASTIN, H. (1975) "Women and work." Presented at New Directions for Research on Women, Madison, WI.

BAKAN, D. (1966) The Duality of Human Existence. Skokie, IL: Rand McNally.

BERNARD, J. (1964) Academic Women. New York: New American Library.

BRODSKY, A. (1974) "Women as graduate students." Amer. Psychologist 29 (July): 523-526.

DOWDALL, J. A. and E. BONEPARTH, (1979) "Mentors in academia: the perceptions of proteges." Presented at the meetings of the American Sociological Association, Boston.

FELDMAN, S. D. (1974) Escape From the Doll's House: Women in Graduate and Professional School Education. New York: McGraw-Hill.

FRIEZE, I. H., J. E. PARSONS, P. JOHNSON, D. N. RUBLE, and P. ZELLMAN, (1978) Women and Sex Roles. New York: Norton.

HOLMSTROM, E. and R. W. HOLMSTROM (1974) "The plight of the woman doctoral student." Amer. Educ. Research J. 11 (Winter): 1-17.

HORNIG, L. (1979) Climbing the Academic Ladder. Washington, DC: National Academy of Sciences. 
KANTER, R. M. (1977) Men and Women of the Corporation. New York: Basic Books.

KJERULFF, K. H. and M. R. BLOOD (1973) "A comparison of communication patterns in male and female graduate students." J. of Higher Education 44 (November): 623-632.

LIPMAN-BLUMEN, J. and H. J. LEAVITT (1976) "Vicarious and direct achievement patterns in adulthood." The Counseling Psychologist 1: 26-32.

MANDELL, R. (1977) The Professor Game. Garden City, NY: Doubleday.

MARINI, M. M. and E. GREENBERGER (1978) "Sex differences in occupational aspirations and expectations." Sociology of Work and Occupations 5 (May): 151174.

PARSONS, J. and S. B. GOFF (1978) "Achievement motivation and values: an alternative perspective." Michigan Occasional Paper III (Fall).

RESKIN, B. (1978) "Sex differentiation and the social organization of science." Sociological Inquiry 48: 6-37.

SELL, L. W. (1973) "Preliminary report on the status of graduate women: University of California, Berkeley." Graduate Assembly of the University of California, Berkeley.

STEIN, A. H. and M. N. BAILEY (1977) "Socialization of achievement orientation in females." Psych. Bull. 80: 345-366.

VAUGHTER, R., D. GUBERNICK, J. MATOSSIAN, and B. HASLETT, (1974) (1974) "Sex differences in academic expectations and achievement." Presented at the meetings of the American Psychological Association, New Orleans.

VEROFF, J. (1977) "Process vs. impact in men's and women's motivations." Psychology of Women Q. 1: 283-293.

WILLIAMS, T. H. (1972) "Educational aspirations: longitudinal evidence on their development in Canadian youth." Sociology of Education 45 (Spring): 107-138.

WYLIE, P. C. (1963) "Children's estimates of their schoolwork ability as a function of sex, race, and socioeconomic level." J. of Personality 63: 202-224.

MARY FRANK FOX is a Lecturer in Sociology at the University of Michigan. Her research has centered on issues of stratification in organizations and occupations. Recent publications include articles on sex differences in the reward structure within academia. Currently, she and Catherine Faver are conducting a study of work behavior and attitudes among social scientists in academia.

CATHERINE A. FAVER is Assistant Professor, Graduate School of Social Work, University of Texas at Arlington. Her research interests include the family, career, and educational patterns of women, especially professional women. She is currently collaborating on two studies investigating the work behavior and attitudes of academic social scientists and social work educators. 